\title{
Sticky point temperature as a suitable method in evaluation of shelf life of food powders
}

\author{
Neda HASHEMI $^{1}$, Elnaz Milani ${ }^{2}$, Seyed Ali MorteZAvi $^{3}$, Faride Tabatabayi YAZDi ${ }^{3}$ \\ ${ }^{1}$ Young researchers and elite club, Sabzevar Branch, Islamic Azad University, Sabzevar, Iran. \\ ${ }^{2}$ Department of Food Processing, Academic Center for Education Culture and Research (ACECR), \\ Mashhad, Iran \\ ${ }^{3}$ Department of Food Science and Technology, Faculty of Agriculture, Ferdowsi University of \\ Mashhad, Mashhad, Iran
}

\begin{abstract}
Based on the maintenance of quality of a product in terms of nutritional value, flavor, texture and appearance during storage, the evaluation of shelf life of food is a necessity. The shelf life of food powders depends on the physical changes and their stickiness. This is an importance phenomenon during production, packaging and distribution. Stickiness reduces the quality and efficiency. This study is aimed to evaluate applied methods to control the temperature in which stickiness is occurred. This study evaluates different methods of measuring Sticky point temperature of food powders and the relationship between this temperature and glass transition temperature, storage environmental conditions and quality of food powders can be expressed. The results show the relationship between the increase of environmental moisture and reduction of sticky point temperature. This study aims to evaluate the applied methods to monitor the temperature at which stickiness is occurred. This study evaluates different methods of measuring sticky point temperature of food powders and the relationship between this temperature and glass transition temperature, storage environmental conditions and quality of food powders is expressed. The results show the relationship between the increase of environmental moisture and reduction of sticky point temperature and reduction of glass transition temperature of food powders. Also, by reduction of sticky point temperature, shelf life of food powder is reduced. By suitable control and measurement of sticky point temperature, the shelf life of food powders can be increased.
\end{abstract}

Keywords: glass transition temperature, sticky point temperature, food powder, shelf life

\section{Introduction}

Consumers tend to use food powers not leading to stickiness and caking during the storage but quality loss as sticky particles, particle surface to stick to the surface of equipment and packages is not considered but it is unavoidable in most cases [1]. Stickiness is a phenomenon that reflects the propensity of powders to agglomerate and to adhere to contact surfaces. Stickiness has positive and negative effects. Granulation or controlled agglomeration of particles during preparation of instant powders like instant coffee, milk powders in which the adhesion of particles leads to good structure. This is the positive point of this process. For example, in instant coffee powders, dried milk powder, and fruit juice powders, agglomeration is often required to enlarge particle size, generally from $50-80 \mu \mathrm{m}$ to 
250-300 $\mu \mathrm{m}$, in order to obtain good 'instant powder' properties such as wetability, dispersibility, and solubility. In addition, stickiness is one of the problems in powders in production process namely during drying, packaging and distribution [2].

\section{Sticky point temperature}

Sticky point temperature is the temperature at which powder particles are adhered to each other, to the surface of equipment and packages. At this temperature, the product bulk shows the maximum resistance against flowing [1]. Stickiness is a stage in which liquid bridge between powder particles is formed (Figure 1). Thus, these particles bridges stick to each other and the liquid bridges can be achieved from the melted fat, amorphous sugar or strong sugar solution [3]. If the liquid bridges are converted into solid and crystal bridges, the powders enter caking stage $[4,5]$. The tendency of powder particles to stick to each other and to surfaces such as dryer wall, and packages is known as stickiness. Thus, the term stickiness includes two issues, cohesive and adhesive stickiness. The sticky interaction between similar surfaces is known as cohesive stickiness. Adhesive stickiness is the sticky interaction between dissimilar surfaces. It is the tendency of particle surface to stick to the surface of equipment and packages. Thus, stickiness is a combination of both processes. For example, in caking process, cohesiveness and in particles sticking to package, adhesion is dominant. In the production process and storage of food powders, cohesive and adhesive interactions are so related that it is quite hard to distinguish the contribution of one against the other [1].

\subsection{The significance of sticky point temperature}

As shown in Figure 1, in powder materials, at first stickiness is created and then the powder is caked and finally a compact solid material is created. These changes lead to the reduction of sensory and practical features of food [6]. Thus, awareness of cohesive and adhesive forces to avoid or reduce them and for better flowing of the powders and the design of machineries is necessary [7].

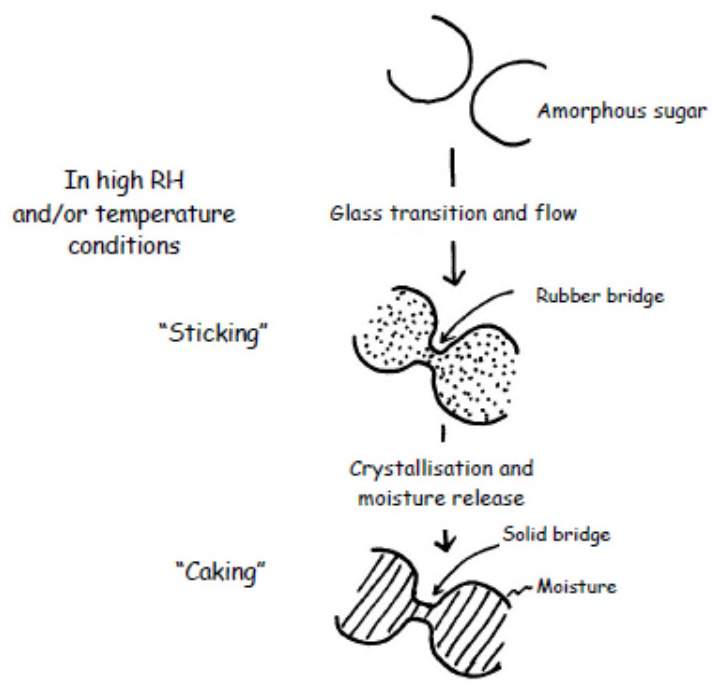

Fig. 1: The stages of stickiness and caking in amorphous sugar particles 
Stickiness and caking are some encountered problems in food powders and other sugar-rich powders which are amorphous [2]. Stickiness problems in the majority of powders are mostly due to the presence of sugar with low molecular weight as sucrose, glucose and fructose or organic acids and besides absorption of moisture have low glass transition temperature, low melting point and high dissolution in water [8,9]. Stickiness and caking are associated to the structure collapse and most of these collapses are affected by moisture content dependent upon time [10]. The mechanisms of particle stickiness and agglomeration are mostly due to intermolecular and electrostatic forces, liquid bridges, solid bridges, or mechanical interlocking of particles. Food and biological powders often contain amorphous carbohydrates that undergo physical changes such as crystallization, clumping, sticking, and caking during drying and stickiness and caking in processing [2,9].

\subsection{The impact of food compound on stickiness}

\subsubsection{Amorphous sugar}

Amorphous sugar in glass transition stage leads to caking. In this stage, amorphous molecules are converted from glass shape to rubber and the flowing and bridging are increased. In high of glass transition temperature, crystallization of amorphous sugar and solid bridges among the particles are increased and this leads to caking of the powder [3, 11].

\subsubsection{Fat}

At high temperature of storage, due to the fat melting and their exit from the food matrix, the fat bridges among the particles are formed and if the temperature is reduced in the next stages, these bridges are turned into solid bridges and stickiness and caking are increased and high fat in chocolate cream powder is created [11].

\subsubsection{Proteins}

Although the effect of proteins on stickiness is not clear, as proteins absorb water and enter the reactions leading to water absorption, they are effective on this property. These effects are due to the formation of thiol-disulfid bonds, covalent bond (by lysine amino acid) and noncovalent bonds. Some problems of powder products as soya, fish powder and whey powder are reported $[12,13]$.

\subsection{The relationship between sticky point temperature and glass transition temperature}

Glass transition temperature is the point at which amorphous food enters from glassy state to rubbery state and in this stage; physical changes as agglomeration, caking and structure collapse are increased [15]. The foods with low molecular weight have weak stability at high temperature of glass transition and stickiness is occurred rapidly. The powders stickiness at above the temperature $10-20^{\circ} \mathrm{C}$ and caking at $20-30 \mathrm{C}$ higher than glass transition are increased (Figure 2)[4,15]. If the viscosity of particles surface of most of amorphous powder food is reduced to 108pa.s, stickiness is shown at particles surface. According to the reports, this temperature interval is $10-20^{\circ} \mathrm{C}$ higher than glass transition temperature. For example, 
the reported values of powder milk is $14-22{ }^{\circ} \mathrm{C}$ and for amorphous lactose more than $19{ }^{\circ} \mathrm{C}$ above the glass transition temperature $[3,16]$.

The strategies presented for stickiness control include: 1) Modification of food behavior, 2) Optimization of production process [17]. Low glass transition temperature leads to the stickiness increase in powders and it is of great importance to modify the behavior of food, high molecular weight compounds as Malto dextrins and lactose are used in food components to increase viscosity, to reduce crystallization, to improve drying characteristics, to decrease hygroscopicity, and to decrease stickiness $[2,18]$. By determining the moisture content, sticky point temperature of food is predicted as a function of storage temperature and sticky point moisture as critical moisture of food quality during storage. Also, the maximum food storage temperature is achieved based on sticky point temperature and moisture of this point [18]. Also, as the stability of amorphous products is associated with the glass transition temperature and this temperature is considered as a function of storage conditions as water and moisture activity. Thus, by controlling environmental conditions of amorphous products, their stability is controlled [19,20].

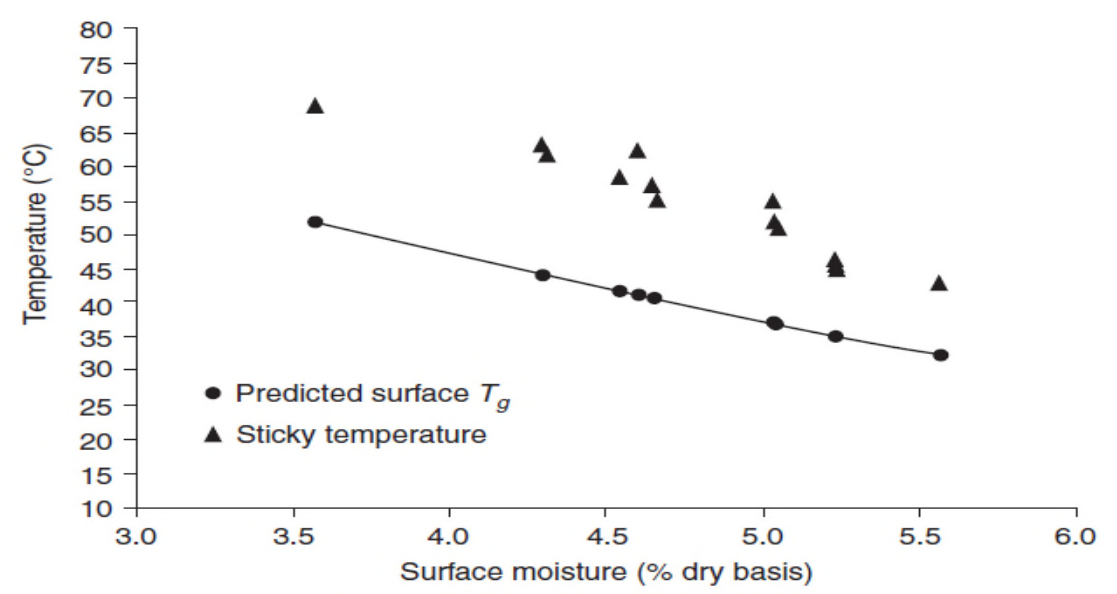

Fig. 2: The changes of glass transition temperature and sticky point temperature by the increase of moisture and temperature

\subsubsection{The measurement methods of sticky point temperature}

Sticky point temperature is measured by two direct and indirect methods (Figure 3). Direct methods include the measurement of shear force changes, viscosity, optimal characteristics, cohesiveness and adhesion of powder as dependent upon temperature and moisture. In conventional methods, stickiness behavior is evaluated using impeller driven, shear cell, ampule and optimal probe. Pneumatic techniques create suspending particles in air flow inside test cells. In insitu technique, the development of cohesion or adhesion of humid surface is considered in moisture elimination process [1]. Indirect methods are based on the control of glass transition temperature being used to evaluate the qualitative characteristics of food and evaluation of the characteristics of powders and its relationship with caking and stickiness phenomena. One of the indirect methods is thermal compression as one of the simplest techniques to evaluate glass transition temperature of food. In this method, compressive force in fixed strain is applied on a thin layer of powder with controlled 
temperature. The temperature at which force is lost rapidly is glass transition temperature. Also, Differential Scanning Calorimetry (DSC) is efficient in this regard [1].

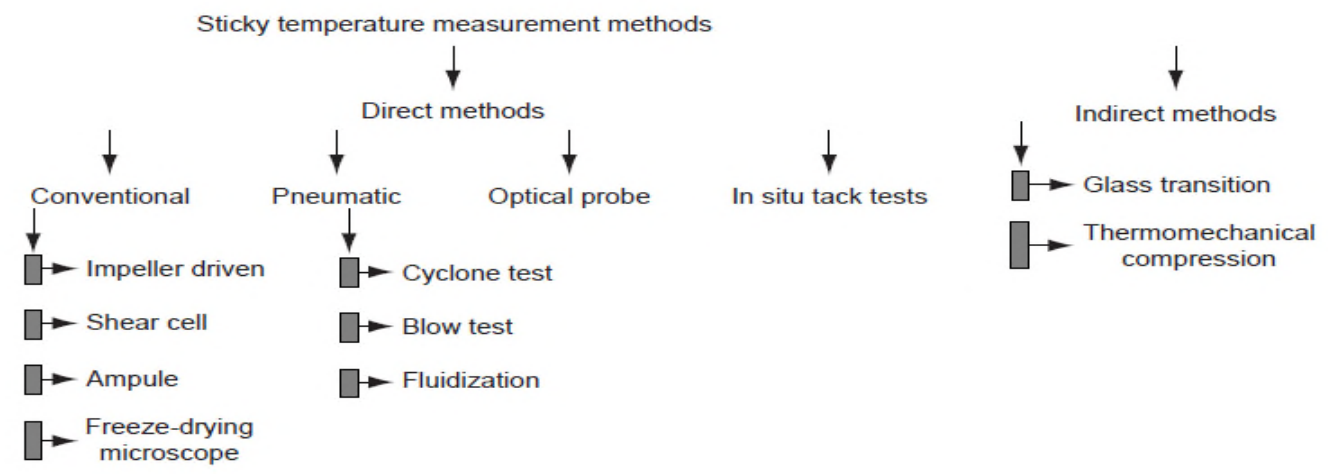

Fig. 3: Different methods of measuring of sticky point temperature

\section{Conclusion}

During drying and storage of powders, stickiness and caking reduce the quality of food. These unsuitable changes are performed based on glass transition temperature as recognized as the most important factor in the quality loss of powders. By the control of particles surface temperature and environment moisture as effective factors on glass transition temperature or using high molecular weight compounds, sticky point temperature can be controlled well.

\section{References}

[1] Shafiur Rahman, M. 2008. Food Properties Handbook, Second Edition, CRC press.347380 .

[2] Bhadra, R., Rosentrater, K. A. \& Muthukumarappan, K. 2013. Measurement of sticky point temperature of coffee powder with a rheometer. International Journal of Food Properties. 16(5):1071-1079.

[3] Foster, K.D., Bronlund, J.E. \& Paterson, A.H.J. 2006. Glass transition related cohesion of amorphous sugar powders. Journal of Food Engineering. 77: 997-1006.

[4] Silalai, N and H. Roos, Y. 2010. Roles of Water and Solids Composition in the Control of Glass Transition and Stickiness of Milk Powders. Journal of Food Science. 75(5): E285-296.

[5] Aguilera, J.M., Del Valle, J.M., Karel, M., 1995. Caking phenomena in amorphous food powder. Trends in Food Science and Technology. 6 (5):149-155.

[6] Jagannadha Rao, P V K., Das, M. \& Das, S K. 2010. Effect of moisture content on glass transition and sticky point temperatures of sugarcane, palmyra-palm and date-palm jiggery granules. International Journal of Food Science and Technology. 45: 94-104.

[7] Fitzpatrick, J. J., Hodnett, M., Twoney, M., Cerqueira, P. S. M., O’Flynn, J. \& Roos, Y. H. 2007. Glass transition and flowability and caking of powders containing amorphous lactose. Powder Technology. 178(1): 119-128. 
[8] Goula, A. M. \& Adamopoulos, K. G. 2010. A new technique for spray drying orange juice concentrate. Innovative Food Science and Emerging Technologies. 11: 342-351.

[9] De Santana, R F ., De Oliveira Neto, E R ., Santos, A, V,. Soares, C. M. F., Lima, A S. \& Cardoso, J.C. 2015. Water sorption isotherm and glass transition temperature of freeze-dried Syzygium cumini fruit (jambolan), J Therm Anal Calorim. 120:519-524

[10] Le Meste, M., Champion, D., Roudaut, G., Blond, G. \& Simatos, D. 2002. Glass transition and food technology: a critical appraisal. Journal of Food Science. 67(7): 24442458.

[11] Crofskey, C. M. 2000. Investigation in to the caking problems Associated with Spray Drier Cream Powders 55 to 70. Massey University, Palmerston North.

[12] Liu W. R., Langer, R and Klibanov, A. M.1991. Moisture induced aggregation of lyophilized protein in the solid state. Biotechnology and Bioengineering. 37: 177-184.

[13] Netto, F. M., Desobry, S.A., and Labuza, T. P. 1998. Effect of water content on the glass transition, caking and stickness of protein hydrolysatees. International Journal of Food Properties. 1(2): 141-161.

[14] Kurozawa , L E., Park, K J. and Hubinger, M D. 2009. Effect of maltodextrin and gum arabic on water sorption and glass transition temperature of spray dried chicken meat hydrolysate protein. Journal of Food Engineering. 91: 287-296.

[15] Ozmen, L. and Langrish, T.A.G. 2002. Comparison of glass transition temperature and sticky point temperature for skim milk powder. Drying Technology. 20: 1173-1188.

[16]Roos, Y.H. 1995. Glass transition-related physicochemical changes in foods. Food Technol. 10: 97-102.

[17] Fitzpatrick, J.J. and Ahrne, L. 2004. Food powder handling and processing: Industry problems, knowledge barriers and research opportunities . Chemical Engineering and Processing. 44 : 209-214.

[18]J aya S., Das H., and Mani S. 2006. Optimization of maltodextrin and tricalcium phosphate for producing vacuum dried mango powder. Int. J. Food Prop. 9:13-24.

[19] Shrestha, A.K., Howes, T., Adhikari, B.P. \& Bhandari, B.R. 2007. Water sorption and glass transition properties of spray dried lactose hydrolysed skim milk powder. LWT-Food Science and Technology. 40: 1593-1600.

[20] Jaya, S. and Das, H. 2005. Accelerated storage, shelf life and color of mango powder. Journal of Food Processing and Preservation. 29: 45-62. 